\title{
Robust Control Applied to a Photovoltaic Array Emulator Using Buck Converter
}

\author{
L. P. Sampaio and S. A. O. Silva \\ Federal Technological University of Paraná - UTFPR-CP \\ Department of Electrical Engineering \\ Av. Alberto Carazzai, 1640, CEP-86300-000 Cornélio Procópio-PR (Brazil) \\ Phone: +55 (43) 3520-4000, Fax: +55 (43) 3520-4010 - E-mails: sampaio@utfpr.edu.br , augus@utfpr.edu.br
}

\begin{abstract}
Considering the increasing use of photovoltaic energy in the actual scenario of electrical power generation, this paper presents the design of an electronic emulator which is able to emulate the characteristics of a PV array. The proposed photovoltaic array emulator is implemented using a mathematical model that represents the equivalent electrical circuit of a photovoltaic cell. The reference signal is obtained from the mathematical model obtained for controlling the dc-dc buck converter, which is used to reproduce the characteristic PV curve (current-voltage). The controller is designed by means of linear matrix inequalities (D-stability criteria in conjunction with $\mathrm{H} \infty$ constraints), considering uncertain parameters in the converter model. Finally, from computer simulations, the proposed work can emulate the PV behavior considering atmospheric variations, such as solar radiation and temperature, in order to evaluate the performance of the system and to validate the proposal of the work.
\end{abstract}

\section{Key words}

PV Emulator, Photovoltaic Array, Robust Control, Linear Matrix Inequalities.

\section{Introduction}

In the last years, a new scenario of electrical power generation has been growing by means of alternative and renewable energies use in conjunction with the utility grid as a distributed generation. Considering the several kinds of renewable energies, the use of photovoltaic energy can be highlighted in the scenario of electrical power generation [1-3].

The electrical power disposable at the output terminals of the photovoltaic panel depends on the manufacturing characteristic and the atmospheric conditions, such as temperature and solar radiation [3]. The temperature is directly related with the PV voltage, such that the increasing of the temperature reduces the PV voltage, while the PV current keeps almost constant. On the other hand, the solar radiation is directly related with the PV current, such that reducing the solar radiation implies in the PV current decreasing, while the PV voltage keeps almost constant. Besides, the relationship between the PV array current and voltage is non linear. The influences of temperature and solar radiations can be observed in Figures 1.a and 1.b, which were obtained considering the behavior of solar panel of SolarWorld Sunmodule Plus SW 245 PV array (Table I).

This work aims to implement, by means of numerical simulations, an equipment that emulates the PV array behavior, considering different levels of solar radiation and temperature, in order to provide high flexibility and/or agility in the design development involving the use of PV array in its applications, such as the evaluation of maximum power point tracking techniques, variation of current-voltage and power-voltage profiles, among others [4].

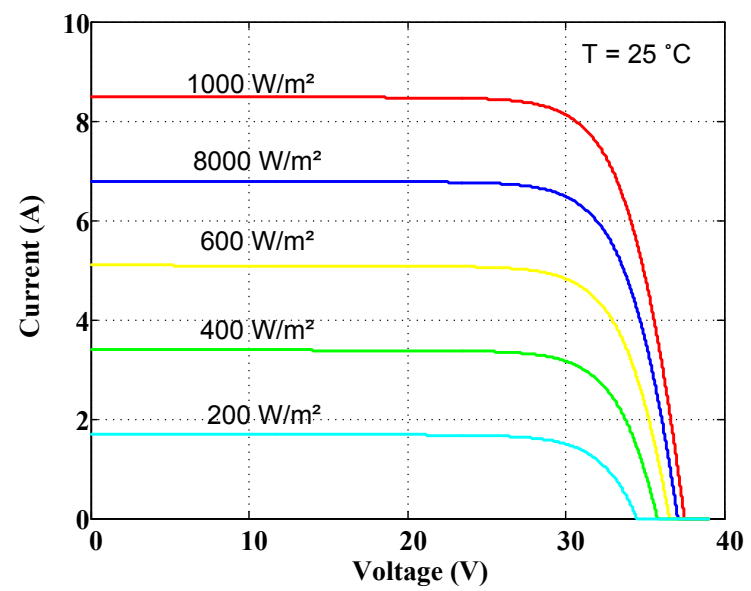

(a)

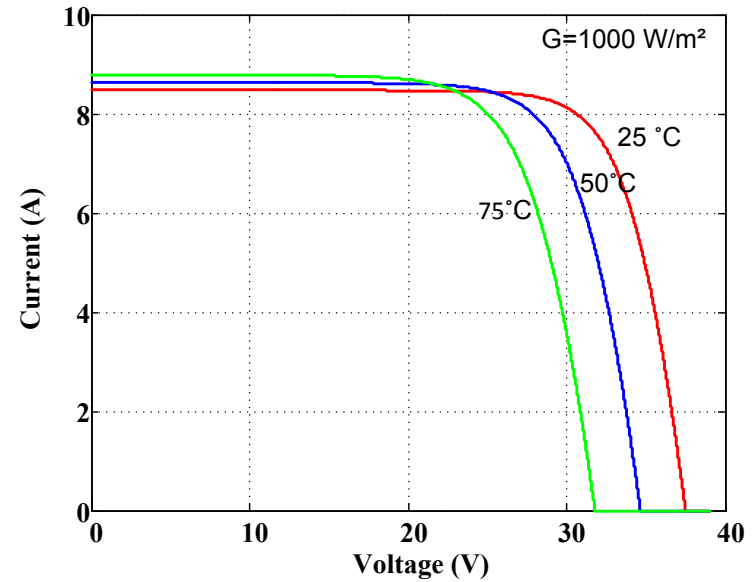

(b)

Fig. 1. (a) Influence of solar radiation in the PV current (b) Influence of temperature in the PV voltage. 


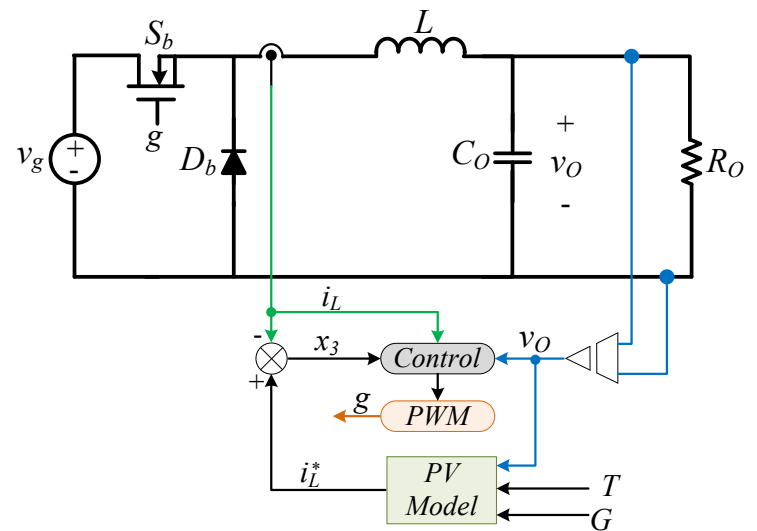

Fig. 2. Schematic circuit of the electronic PV array emulator.

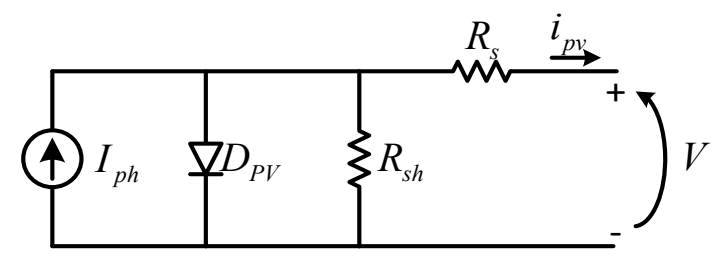

Fig. 3. Equivalent circuit of the solar photovoltaic cell.

The proposed photovoltaic array emulator is composed of a dc-dc Buck converter, which is controlled to obtain the relationship between the current and voltage of the PV array, which can be represented by its characteristic curve. By means of the mathematical model the relationship is obtained based on the PV array curves (IxV and PxV) and its model depends on the temperature, solar radiation, as well as the output at the output terminals of the PV array. Furthermore, the dc-dc converter is controlled by using robust control, which is designed by linear matrix inequalities (LMI) together with D-stability criteria and $\mathrm{H} \infty$ constraints [5-7]. In addition, the dc-dc converter is tested in order to evaluate and to validate the proposed theoretical development.

\section{Proposed PV Array Emulator}

The electronic PV array emulator scheme is shown in Figure 2.

\section{A. PV Model System}

In order to implement a PV emulator, it is necessary to understand and to comprehend the functionality of the PV system [8-9]. In this work, it is adopted an equivalent electrical circuit to represent a PV cell, as shown in Figure 3. This model is composed of a current source $\left(I_{p h}\right)$, a diode $\left(D_{P V}\right)$ and series $\left(R_{S}\right)$ and shunt $\left(R_{s h}\right)$ resistances

The PV cell output current is given by (1).

$$
i_{p v}=I_{p h}-I_{r}\left[e^{q \frac{V+I R_{S}}{\eta k T}}-1\right]-\frac{V+I R_{S}}{R_{s h}}
$$

where $V$ is the output voltage of the PV cell terminals; $I_{p h}$ and $I_{r}$ are the photocurrent and the reverse saturation current, given by (2) and (3), respectively; $q$ is the electron charge; $\eta$ is the ideality factor of the junction $\mathrm{p}-\mathrm{n} ; k$ is the
Boltzmann constant; $T$ represents the ambient temperature, in Kelvin.

$$
\begin{aligned}
I_{p h} & =\left[I_{S C}+\alpha\left(T-T_{r}\right)\right] \frac{G}{1000} \\
I_{r} & =I_{r r}\left(\frac{T}{T_{r}}\right)^{3} e^{\left[\frac{q E g}{A k}\left(\frac{1}{T_{r}}-\frac{1}{T}\right)\right]}
\end{aligned}
$$

where $T_{r}$ is the nominal temperature $(298 \mathrm{~K}) ; I_{S C}$ is the short circuit current at Standard Test Conditions (STC) $\left(T_{r}=25^{\circ} \mathrm{C}\right.$, and $\left.G=1000 \mathrm{~W} / \mathrm{m}^{2}\right) ; \alpha$ is the temperature coefficient; $I_{r r}$ is the diode reverse saturation current; and $E_{g}$ is the band gap energy $(1.1 \mathrm{eV})$, and $G$ represents the power density of the solar radiation.

The diode reverse saturation current $I_{r r}$ and the PV array voltage $V_{P V}$ are given by (4) and (5), respectively.

$$
\begin{gathered}
I_{r r}=\frac{I_{S C}-\frac{V_{O C}}{R p}}{e^{\frac{q V_{O C}}{A k T r}}}-1 \\
V_{P V}=V N s M s
\end{gathered}
$$

where $V_{o c}$ is the open circuit voltage of the photovoltaic cell; $N S$ is the number of photovoltaic cell; and $M S$ is the number of the PV arrays connected in series.

The PV cell current $\left(i_{p v}\right)$ given by (1), cannot be algebraically solved, due to the nonlinear relationship between $i_{p v}$ and $V$. In this case, $i_{p v}$ is obtained by using the Newton-Raphson numeric method [8-9].

\section{B. System Modelling}

In order to design the system controller via LMIs approaches, it is necessary to obtain the state-space equations that represent the system modelling. Figure 4 shows the electrical circuit of the Buck converter used to emulate the PV array.

The LMI constraints are usually expressed in terms of state-space variables (6).

$$
\left\{\begin{array}{l}
\dot{x}(t)=A x(t)+B_{w} w(t)+B_{u} u(t)+B_{\text {ref }} I_{\text {ref }} \\
y(t)=C x(t)
\end{array}\right.
$$

where $A \in \mathbb{R}^{n \times n}$ is the state matrix; $B_{w} \in \mathbb{R}^{n \times r}$ is the disturbance matrix; $B_{u} \in \mathbb{R}^{n \times m}$ is the control matrix; $C \in \mathbb{R}^{p \times n}$ is the output matrix and

$$
\begin{aligned}
& x(t)=\left[\begin{array}{l}
i_{L}(t) \\
v_{O}(t) \\
x_{3}(t)
\end{array}\right], w(t)=\left[i_{\text {Load }}\right], u(t)=[d(t)], \\
& y(t)=\left[i_{L}(t)\right]
\end{aligned}
$$

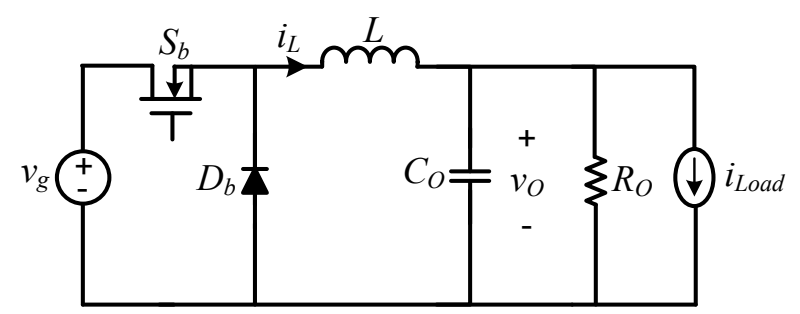

Fig. 4. Schematic diagram of Buck Converter. 
The state variable $x_{3}$ is the integral of the error obtained from the difference between the current reference $\left(I_{r e f}\right)$ and the inductor current $\left(i_{L}\right)$. The matrices that represent the state-space of Buck converter (Figure 4) are given by (7) [10].

$$
\begin{gathered}
A=\left[\begin{array}{ccc}
0 & -\frac{1}{L} & 0 \\
\frac{1}{C_{O}} & -\frac{1}{R_{O} C_{O}} & 0 \\
-1 & 0 & 0
\end{array}\right], B_{w}=\left[\begin{array}{c}
0 \\
-\frac{1}{C_{O}} \\
0
\end{array}\right], B_{u}=\left[\begin{array}{c}
\frac{V_{g}}{L} \\
0 \\
0
\end{array}\right] \\
B_{\text {ref }}=\left[\begin{array}{l}
0 \\
0 \\
1
\end{array}\right], C=\left[\begin{array}{lll}
0 & 1 & 0
\end{array}\right]
\end{gathered}
$$

In this paper it is considered that both the load $\left(R_{O}\right)$ and the buck input voltage $\left(V_{g}\right)$ are uncertain or time-varying parameters, while the other parameters are well-known.

The controller is designed considering the control law defined by the state-feedback gain $K$, given by (9).

$$
u(t)=K x(t)
$$

\section{Controller Design}

This work deals with a controller design via LMIs approach, considering three constraints: quadratic stability (Lyapunov base stability), pole placement (well-known as D-stability) and $\mathrm{H} \infty$ constraint [6].

The LMIs engaged in the solution of convex optimization problems are widely discussed in the literature and the theoretical background of them are detailed in [6-7]. Therefore, in this paper, they will only be summarized.

\section{A. Quadratic Stability}

Considering a closed-loop system with state-feedback $u=K x$, the Quadratic Stability in Lyapunov sense can be expressed as an LMI given by (10).

$$
\begin{gathered}
W>0 \\
A W+W A^{\prime}+B_{u} Y+Y^{\prime} B_{u}^{\prime}<0
\end{gathered}
$$

From (10), will exist a state feedback $u=K x$ that establishes the system if and only if there exists a symmetric matrix $W \in \mathbb{R}^{n \times n}$ and a matrix $Y \in \mathbb{R}^{m \times n}$, where the state feedback is given by $K=Y W^{-1}$.

\section{B. Pole Placement}

The pole placement is a simple way to ensure the system performance, allocating poles in a defined region of the complex plane $S$ for the closed-loop system, in order to guarantee some desired dynamic behaviour, such as overshoot and settling time. Figure 5 shows the region $S(\alpha$, $\mathrm{r}, \theta$ ) for pole placement.

The region $\mathrm{S}$ is defined by the real part of the pole $\alpha$, the angle $\theta$ and pole magnitude $r$.

Theorem 1: The closed loop poles of the system (6) according to the control law, $u=K x$, are inside the region
$S(\alpha, \rho, \theta)$ if exist a symmetric positive definite matrix $\mathrm{W}$ and a matrix Y such (10), (11) and (12).

$$
\begin{gathered}
A W+W A^{\prime}+B_{u} Y+Y^{\prime} B_{u}^{\prime}+2 \alpha W<0 \\
{\left[\begin{array}{cc}
-\rho W & W A^{\prime}+Y^{\prime} B_{u}^{\prime} \\
A W+B_{u} Y & -\rho W
\end{array}\right]<0} \\
{\left[\begin{array}{l}
\sin \theta\left(A W+W A^{\prime}+B_{u} Y+Y^{\prime} B_{u}^{\prime}\right) \\
\cos \theta\left(W A^{\prime}-A W-B_{u} Y+Y^{\prime} B_{u}^{\prime}\right) \\
\cos \theta\left(A W-W A^{\prime}+B_{u} Y-Y^{\prime} B_{u}^{\prime}\right) \\
\sin \theta\left(A W+W A^{\prime}+B_{u} Y+Y^{\prime} B_{u}^{\prime}\right)
\end{array}\right]<0}
\end{gathered}
$$

and $K=Y W^{-1}$ is the state feedback gain.

\section{Hळ constraints}

The Hळ constraints are used with the purpose to limit the frequency gain peak of the transfer function from disturbances $w$ to output $y$, derived as (13).

$$
\|H(s)\|_{\infty} \triangleq \sup _{\omega(t) \neq 0} \frac{\|y\|_{2}}{\|w\|_{2}}
$$

where $\|.\|_{\infty}$ and $\|.\|_{2}$ represents the infinity and the Euclidian norms, respectively.

The LMIs are intended for optimization procedure with $H_{\infty}$ constraint, in order to guarantee a minimum level of disturbance $(\gamma)$. Therefore, the $H_{\infty}$ constraint is represented by means of LMI, according to (14).

$$
\left[\begin{array}{ccc}
A W+W A^{\prime}+B_{u} Y+Y^{\prime} B_{u}^{\prime} & B_{w} & W C^{\prime} \\
B_{w} & -\gamma & 0 \\
C W & 0 & -\gamma
\end{array}\right]<0(14)
$$

\section{PV System Design}

The PV emulator, implemented by means of the software

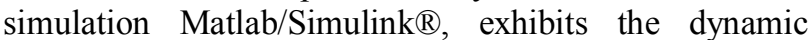
characteristics of the PV array, whose its dynamic behaviour is close to the SolarWorld SunModule SW 245 , where its main parameters are described in Table I.

Table I. - Standard test conditions (STC) of the SolarWorld Sunmodule Plus SW 245 PV array.

\begin{tabular}{|c|l|}
\hline Maximum PV power & $P_{\max }=245 \mathrm{~W}$ \\
\hline Maximum power point voltage & $V_{m p p}=30.8 \mathrm{~V}$ \\
\hline Maximum power point current & $I_{m p p}=7.96 \mathrm{~A}$ \\
\hline Open circuit voltage & $V_{o c}=37.5 \mathrm{~V}$ \\
\hline Short-circuit current & $I_{s c}=8.49 \mathrm{~A}$ \\
\hline
\end{tabular}

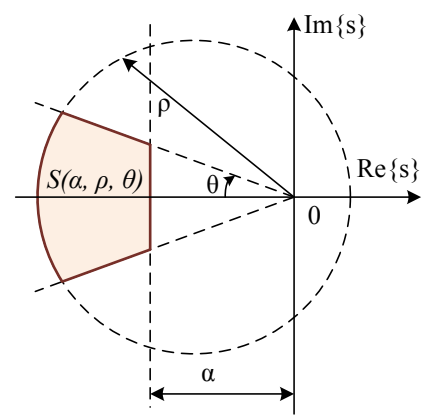

Fig. 5. Definition of a region $S(\alpha, \rho, \theta)$ for pole placement. 


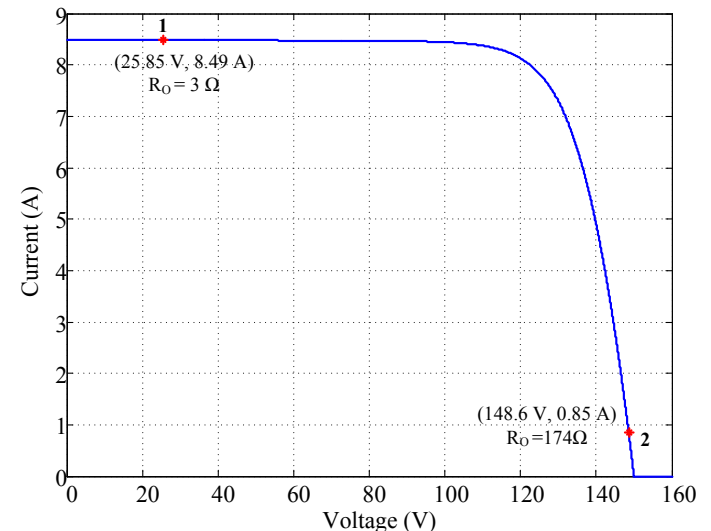

Fig. 6. Uncertain parameters definition by means of $\mathrm{IxV}$ curve.

Table II summarizes the main parameters used in the Buck converter (Figure 2), in order to emulate the PV array behavior. The converter was designed considering that the system can emulate from one up to four series PV modules.

Table II. - Buck converter main parameters.

\begin{tabular}{|c|c|}
\hline Nominal input voltage (avg) & $V_{g}=180 \mathrm{~V}$ \\
\hline Buck output capacitance & $C o=39 \mu \mathrm{F}$ \\
\hline Buck inductance & $L=2.5 \mathrm{mH}$ \\
\hline Switching frequency & $f_{s w}=20 \mathrm{kHz}$ \\
\hline Buck output voltage at MPP & $V_{O}=123.2 \mathrm{~V}$ \\
\hline Buck output current at MPP & $I_{O}=7.96 \mathrm{~A}$ \\
\hline
\end{tabular}

In order to reproduce the PV characteristics, the Buck converter will operate with variables output current $\left(i_{O}\right)$ and voltage $\left(v_{O}\right)$. Thus, in the controller design, these uncertain quantities can be considered, i.e., based on the variations of the output Buck converter resistance, as shown in Figure 6. Thus, it was considered that the Buck converter should represent the PV behavior, which has two distinct points: short-circuit current and open-circuit voltage. Hence, in order to avoid an infeasibility solution, the uncertain quantities was defined in the points $1(25.85$ $\mathrm{V}$ and $8.49 \mathrm{~A})$ and $2(148.6 \mathrm{~V}$ and $0.85 \mathrm{~A})$ for the LMI design.

Furthermore, it was considered that the input voltage of the Buck converter varies from $160 \mathrm{~V}$ to $200 \mathrm{~V}$, taking into account that this dc voltage is supplied from the electrical grid by means of a full-bridge rectifier followed of a capacitor filter. Table III shows the uncertain quantities used in this work.

Table III. - Uncertain parameters for affine dependence.

\begin{tabular}{|c|c|}
\hline PARAMETER & UNCERTAIN RANGE \\
\hline$\beta=\frac{1}{R_{O}}$ & $5.7 \times 10^{-3}$ to $333.3 \times 10^{-3}$ \\
\hline$V_{g}$ & 160 to 200 \\
\hline
\end{tabular}

The D-stability criteria were defined in order to attend practical limitations of the controllers such as bandwidth and overshoot. The maximum bandwidth is limited to be a quarter of the switching frequency, in according with the averaging approximation applied to obtain the matrices of state-space [10]. This limit is considered for the variable $\rho$. The pole placement constraints are listed in Table IV.

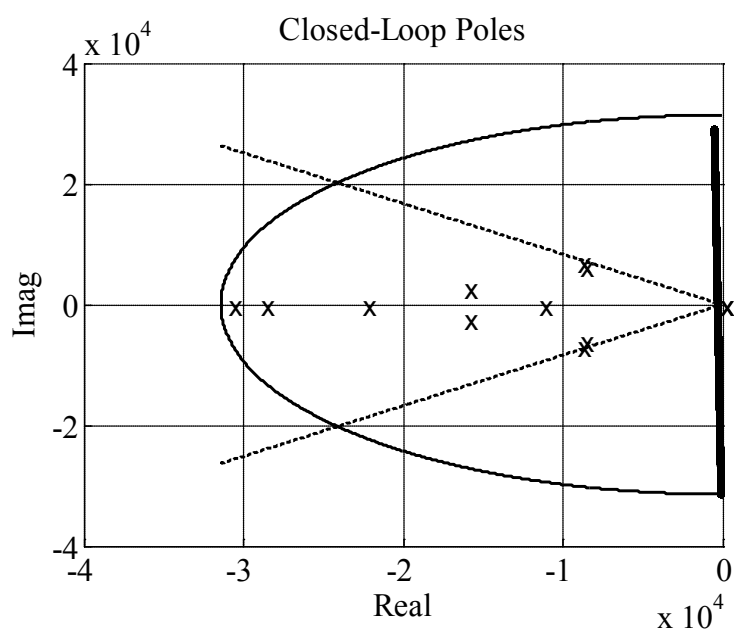

Fig. 7. Closed-Loop Poles for the PV Emulator.

Table IV. - Poles placement parameters.

\begin{tabular}{|c|c|}
\hline PARAMETER & VALUE \\
\hline$\alpha$ & 180 \\
\hline$\rho$ & $\frac{2 \pi}{4 f_{s}}$ \\
\hline$\theta$ & $40^{\circ}$ \\
\hline
\end{tabular}

The state-feedback controller $(K)$ was determined by means of Matlab ${ }^{\circledR}$ in conjunction with Yalmip and SeDuMi toolboxes [11]:

$$
K=\left[\begin{array}{lll}
-0.4945 & 0.056 & 5.37 \times 10^{-3}
\end{array}\right]
$$

Figure 7 shows the closed-loop poles placed in the specified $S$ region of the left-half-plane-s, ensuring that all poles is inside the $\mathrm{S}$ region.

\section{Simulation Results}

This section presents the simulation results for the electronic PV array emulator, considering the following characteristics: load resistance variations at STC, and atmospheric variations taking into account fixed load.

Figure 8-11 show the behavior of the electronic PV array emulator considering the following values of load resistance: $7.5 \Omega, 15.5 \Omega, 30 \Omega, 60 \Omega, 120 \Omega$ and $240 \Omega$, with a solar radiation of $1000 \mathrm{~W} / \mathrm{m}^{2}$ and temperature of $25{ }^{\circ} \mathrm{C}$, considering four series PV panels. Figure 8 shows the reference current (blue) and the tracked current by the inductor (red). As can be observed, the proposed control achieves good results for tracking the desired reference current. Figures 9 and 10 show the output current and voltage in the load. The output power supplied to the resistance is shown in Figure 11.

Figure 12 shows the comparison between theoretical PV array curve obtained by means of mathematical model (blue) with the several point of emulated PV power (asterisk in red) obtained by load resistance changes. As can be noted the proposed electronic PV array emulator can reliable reproduces the PV curve, i.e., it allows good design involving photovoltaic array applications. 


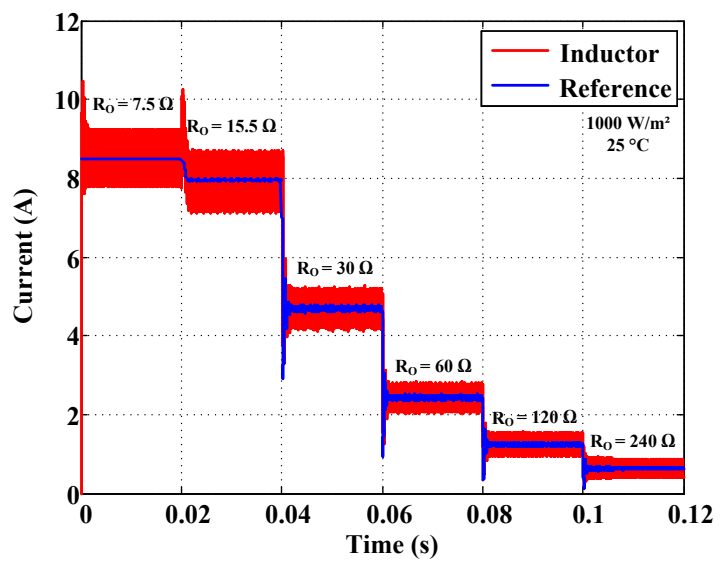

Fig. 8. Reference current and inductor current for several resistance values in STC.

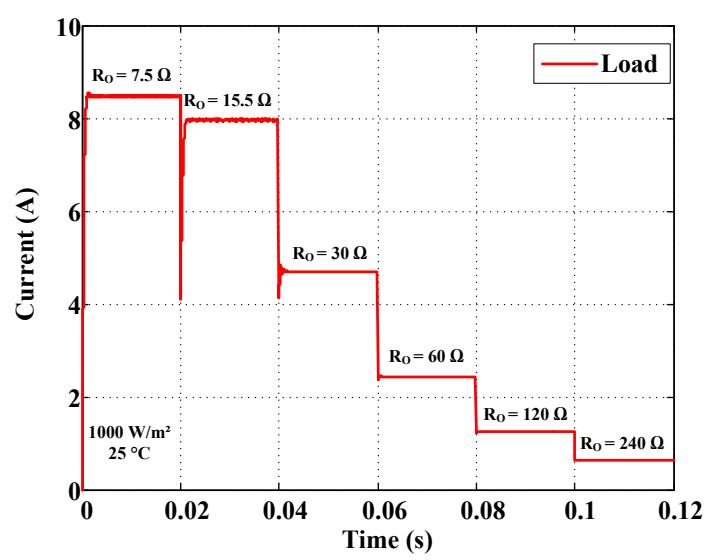

Fig. 9. Output current for several resistance values in STC.

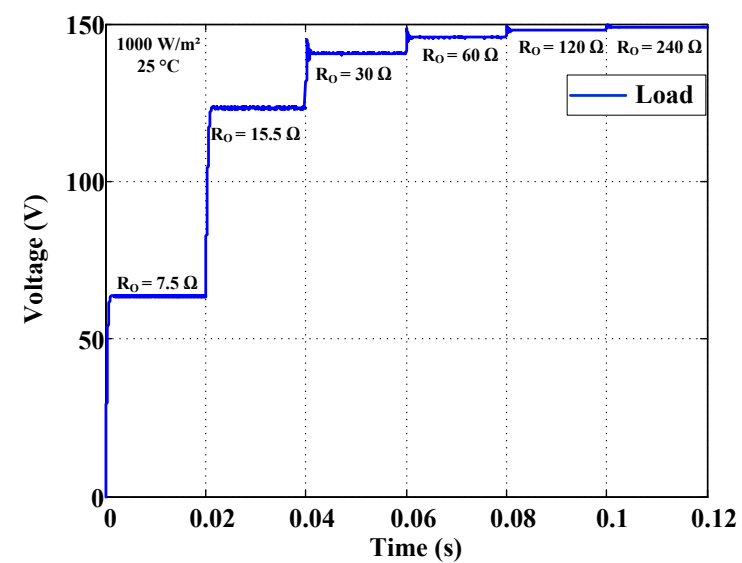

Fig. 10. Output voltage for several resistance values in STC.

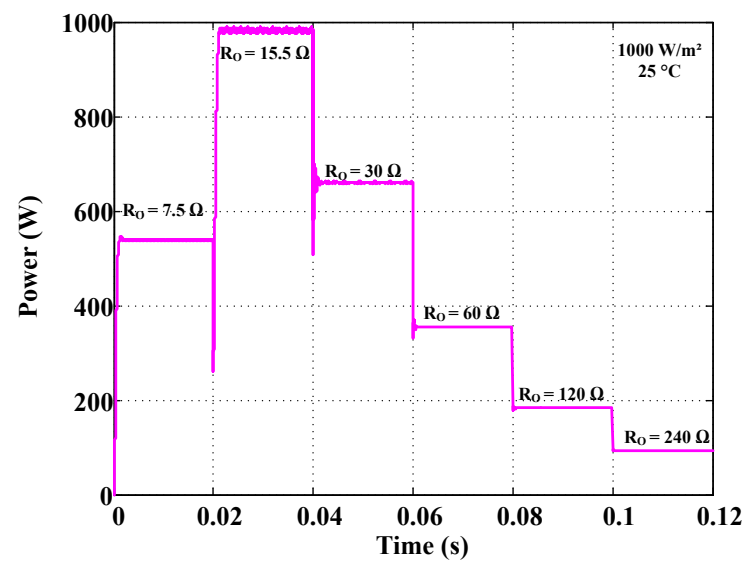

Fig. 11. Output power for several resistance values in STC.

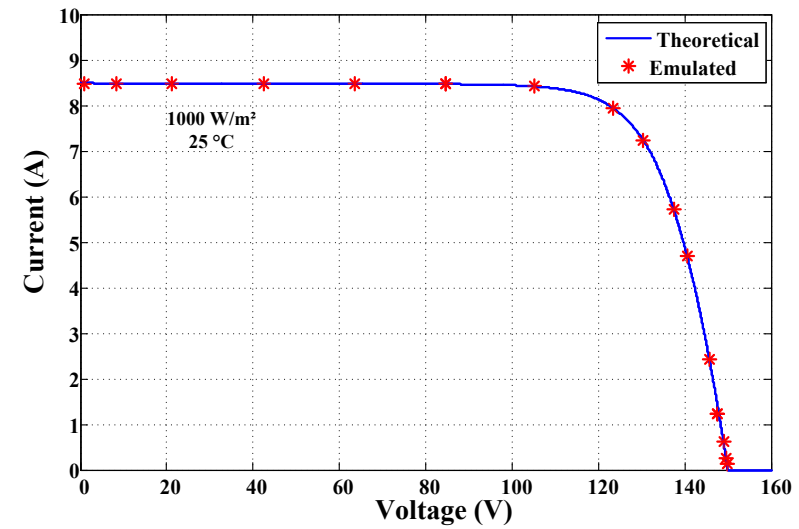

Fig. 12. Comparison between the theoretical PV curve and the emulated power for load resistance changes.

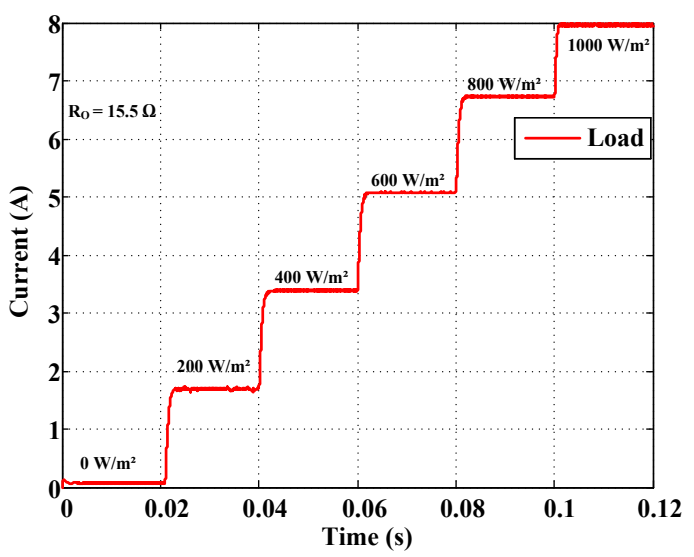

Fig. 13. Output current for several values of solar radiation and temperature, with fixed load resistance.

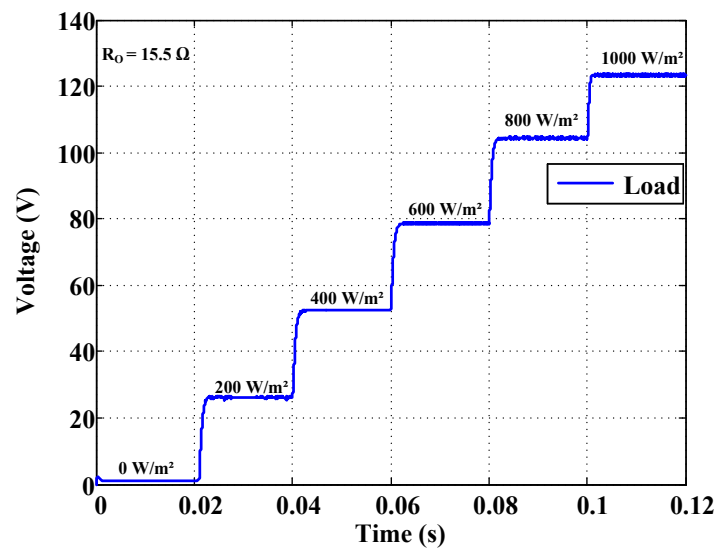

Fig. 14. Output voltage for several values of solar radiation and temperature for fixed load resistance.

The Figures 13 and 14 show the output current and voltage in the load for different values of solar radiation $\left(200,400,600,800\right.$ and $\left.1000 \mathrm{~W} / \mathrm{m}^{2}\right)$ and temperature $\left(10,20,35,40\right.$ and $\left.25^{\circ} \mathrm{C}\right)$ for a fixed resistance of 15.5 $\Omega$, considering four series PV panels. As can be observed, the electronic PV array emulator reproduces the PV array behavior considering changes in the atmospheric conditions.

Figures 15.a and 15.b show the behavior of the electronic PV array emulator considering only one PV panel operating at STC, where the dynamics of the converter were evaluated changing the load resistance $(2,4,8$ and $16 \Omega)$. 


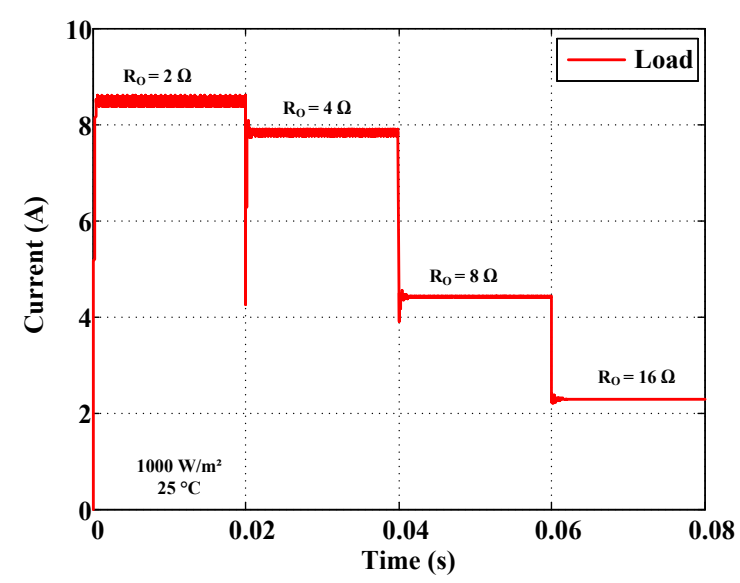

(a)

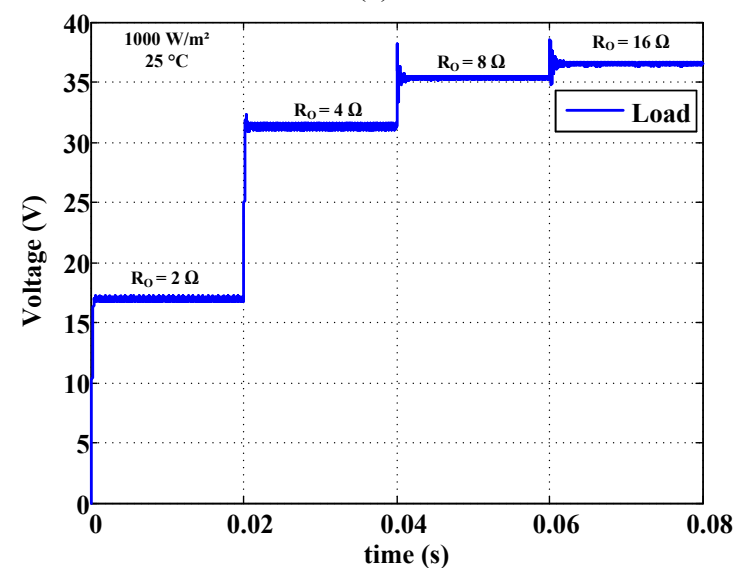

(b)

Fig. 15. Behavior of the electronic PV emulator, considering one PV panel at STC: (a) Output current, (b) Output voltage.

\section{Conclusions}

This paper proposed an electronic PV array emulator, which is able to emulate the behavior of the desired PV array. The system was implemented in simulation software and evaluated considering variation in the atmospheric conditions, such as solar radiation and temperature, assuming typical conditions that the PV panels are subject in the environment. Additionally, given the features of the proposed system, the emulator is able to synthesize different kinds of photovoltaic arrays, as can be seen from the presented simulation results.

The proposed system presents a good dynamic behavior, resulting in a rapid response with low settling time when subjected to parameters variations, such as solar radiation, temperature, as well as load tests at the output of emulator. Already in steady-state the electronic PV array emulator has been demonstrated sufficient to generate the PV curve (current-voltage) at the output of the converter accurately as the characteristic curve of the photovoltaic panel in study.
Moreover, it was presented a control methodology considering uncertainties in the model of the dc-dc buck converter, where the controller gain was obtained using poles placement in conjunction with $\mathrm{H} \infty$ constraint by means of linear matrix inequalities.

Thereby, it was shown that the proposed work is able to accurately reproduce the real characteristics of any photovoltaic panel.

\section{Acknowledgement}

The authors would like to thanks the CNPq (The Brazilian National Council for Scientific and Technological Development) and the Araucária Foundation for the financial support.

\section{References}

[1] R. F. Arritt and R. C. Dugan, "Distribution System Analysis and the Future Smart Grid," IEEE Transactions on Industry Applications, vol. 47, no. 6, pp. 2343-2350, Nov. 2011.

[2] REN21 - "Renewables 2011: Global status report", [s.1.;s.n], Avaliable from: <http://www.ren21.net>, accessed Nov. 2014.

[3] M. A. G. de Brito, L. P. Sampaio, L. Galotto Jr. and C. A. Canesin, "Evaluation of the Main MPPT Techniques for Photovoltaic Applications," IEEE Trans. Industr. Electron., vol. 60, no. 3, pp. 1156-1167, Mar. 2013.

[4] Z. Jie and K. Jonathan W, "A Digitally Implemented Photovoltaic Simulator with a Double Current Mode Controller, " IEEE trans. Indust. Electron., p. 53-58, 2012.

[5] S. Boyd, L. El Ghaoui and E. Feron, V. Balakrishnan, Linear matrix inequalities in system and control theory, Society for Industrial and Applied Mathematics, [s. 1.], vol. $15,1994$.

[6] M. Chilali and P. Gahinet, "Hळ design with pole placement constraints: an LMI approach", IEEE Transactions on Automatic Control, vol. 41, no. 3, pp. 358-367, March 1996.

[7] L. Antonio, M. Jr, J. R. Massing, L. Schuch, C. Rech, H. Pinheiro, and R. C. L. F. Oliveira, "LMI-Based Control for Grid-Connected Converters With LCL Filters Under Uncertain Parameters," IEEE Trans. Power Electron., vol. 29, no. 7, pp. 3776-3785, 2014.

[8] M. M. Casaro and D. C. Martins, "Modelo De Arranjo Fotovoltaico Destinado a Análises em Eletrônica de Potência via Simulação," Revista Eletrônica de Potência, vol. 13, no. 3, pp. 141-146, Aug. 2008 (in portuguese).

[9] Gow J. A and Manning C. D "Development of a Photovoltaic Array Model for Use in Power Electronics Simulation Studies," IEE Proc. on Electric Power Applications, vol. 146, no. 2, pp. 193-200, 1999.

[10] R. Erickson, Fundamentals of Power Electronics, 2nd ed. New Jersey: Kluwer Academinc Publishers, 2000, p. 883.

[11] J. Lofberg, "YALMIP: a toolbox for modeling and optimization in MATLAB", in Proc. of CACSD, vol. 13, pp. 284-289, 2004. 